Article

\title{
First Electrochemical Sensor (Screen-Printed Carbon Electrode Modified with Carboxyl Functionalized Multiwalled Carbon Nanotubes) for Ultratrace Determination of Diclofenac
}

\author{
Agnieszka Sasal ${ }^{1}$, Katarzyna Tyszczuk-Rotko ${ }^{1, *(\mathbb{D}}$, Magdalena Wójciak ${ }^{2, *(1)}$ and Ireneusz Sowa ${ }^{2}$ (i) \\ 1 Faculty of Chemistry, Institute of Chemical Sciences, Maria Curie-Skłodowska University, \\ 20-031 Lublin, Poland; agnieszkaszwagierek@gmail.com \\ 2 Department of Analytical Chemistry, Medical University of Lublin, 20-093 Lublin, Poland; \\ ireneusz.sowa@umlub.pl \\ * Correspondence: ktyszczuk@poczta.umcs.lublin.pl (K.T.-R.); kosiorma@wp.pl (M.W.)
}

Received: 14 January 2020; Accepted: 5 February 2020; Published: 8 February 2020

\begin{abstract}
A simple, sensitive and time-saving differential-pulse adsorptive stripping voltammetric (DPAdSV) procedure using a screen-printed carbon electrode modified with carboxyl functionalized multiwalled carbon nanotubes (SPCE/MWCNTs-COOH) for the determination of diclofenac (DF) is presented. The sensor was characterized using optical profilometry, SEM, and cyclic voltammetry $(\mathrm{CV})$. The use of carboxyl functionalized MWCNTs as a SPCE modifier improved the electron transfer process and the active surface area of sensor. Under optimum conditions, very sensitive results were obtained with a linear range of $0.1-10.0 \mathrm{nmol} \mathrm{L}^{-1}$ and a limit of detection value of $0.028 \mathrm{nmol} \mathrm{L}^{-1}$. The SPCE/MWCNTs-COOH also exhibited satisfactory repeatability, reproducibility, and selectivity towards potential interferences. Moreover, for the first time, the electrochemical sensor allows determining the real concentrations of DF in environmental water samples without sample pretreatment steps.
\end{abstract}

Keywords: screen-printed carbon electrode modified with carboxyl functionalized multiwalled carbon nanotubes; diclofenac; differential-pulse adsorptive stripping voltammetry; environmental water samples; HPLC with photo-diode array detection

\section{Introduction}

Diclofenac (DF) is a nonsteroidal anti-inflammatory drug (NSAID), a derivative of aminophenylacetic acid with a strong anti-inflammatory, analgesic and antipyretic effect. The action of the drug causes the inhibition of inductive (COX-2) cyclooxygenases, responsible for the synthesis of proinflammatory prostaglandins in the site of inflammation and constitutive (COX-1) and the synthesis of prostaglandins fulfilling a physiological function in the gastrointestinal tract and kidneys. DF is absorbed quickly and completely from the gastrointestinal tract and then eliminated completely within $12 \mathrm{~h}$, approximately $60 \%$ in the urine and 33\% in the faeces. DF is used as an analgesic and anti-inflammatory drug in rheumatoid arthritis, other connective tissue systemic diseases, gout attack, osteoarthritis, and the prevention and treatment of postoperative pain and neuralgia. DF is not recommended for children under 12 years of age and for people suffering from gastric and duodenal ulcer, aspirin-induced asthma, impaired hepatic function, renal insufficiency, and porphyria [1].

In autumn and winter seasons, an increased number of colds and flu is observed, which results in a significant increase in the number of sales and the consumption of pharmaceutical preparations, in particular NSAIDs. Residues of drugs and dietary supplements get into the environment primarily 
to ground and surface water, causing their pollution. Low water temperatures and short days hinder the process of photolysis and the biodegradation of pharmaceutical preparations, which can cause adverse and unpredictable effects in the ecosystem. The main sources of pollution are factories and production plants, as well as hospitals, health centers, and practically every household. DF is one of the most commonly found ingredients in water, and its concentration is from $3.7 \times 10^{-11}$ to $1.4 \times 10^{-8} \mathrm{~mol} \mathrm{~L}^{-1}[2,3]$.

Although the likelihood of any form of short-term human health risk after DF release into the environment is low, a study links the catastrophic decline of Gyps vulture populations across the Indian subcontinent to DF [4,5]. Generally, NSAIDs such as DF and ibuprofen, for example, have Log Kow values greater than three and may have the capacity to bioaccumulate in the tissues of organisms [6]. DF exhibits acute hepatotoxicity, causes changes in kidneys and gills in rainbow trout (O. mykiss) and exhibits acute toxicity to phytoplankton and zooplankton. Moreover, the possibility of synergetic effects with other pharmaceuticals or chemicals in the aquatic environment increases the environmental risk as well [7].

There are many methods in the literature that allow for the determination of DF at various concentration levels. The most popular methods are spectrophotometry (determined DF concentrations: $6.8 \times 10^{-7}-8.4 \times 10^{-2} \mathrm{~mol} \mathrm{~L}^{-1}$ ), spectrofluorimetry (determined DF concentrations: $4.2 \times 10^{-7}$ $1.7 \times 10^{-4} \mathrm{~mol} \mathrm{~L}^{-1}$ ), calorimetry (determined DF concentrations: $4.6 \times 10^{-6}-2.7 \times 10^{-4} \mathrm{~mol} \mathrm{~L}^{-1}$ ), high-performance thin-layer chromatography (determined DF concentrations: $6.8 \times 10^{-7}$ $2.7 \times 10^{-6} \mathrm{~mol} \mathrm{~L}^{-1}$ ), and HPLC (determined DF concentrations: $\left.1.7 \times 10^{-8}-1.4 \times 10^{-5} \mathrm{~mol} \mathrm{~L}^{-1}\right)[8,9]$. Unfortunately, these methods require frequently a time-consuming initial sample preparation stage due to very low concentrations of DF in water samples.

An alternative to the methods described above are electrochemical methods that allow for quick and cheap analysis of real samples. In the research, various types of working electrodes are used, the most popular electrodes are glassy carbon electrodes modified with metal [10], graphene and carbon nanomaterials [1,11-14] or organic compounds [15-18]. In addition, paste electrodes [19] modified with carbon nanomaterials [20-24], silica [25] or organic compounds [26], graphite electrodes [27,28], composite electrodes [27,29], carbon ceramic electrodes [30], boron-doped diamond electrodes [31], and platinum disk electrodes [32,33] are used. The methods presented in most cases are applicable in the determination of DF in pharmaceutical preparations and human urine samples and blood samples. According to our knowledge, currently, there are only four papers on the development of electrochemical sensors for the determination of DF in water samples $[15,16,19,31]$. However, the authors of those papers determined DF in spiked water samples at concentrations (around $10^{-7}-10^{-3} \mathrm{~mol} \mathrm{~L}{ }^{-1}$ ) higher than those actually present in environmental samples. This was related to the received limit of detection (LOD) values in a range of $3.0 \times 10^{-8}-2.0 \times 10^{-7} \mathrm{~mol} \mathrm{~L}^{-1}$.

Furthermore, all of the above works describe research methods that are applicable in laboratory analyses. However, no methods have been developed for field analysis. For this purpose, screen-printed sensors can be used. Screen-printing technology allows obtaining a small size of screen-printed sensors, which are characterized by low production cost and high repeatability and allow for the analysis of organic and inorganic compounds at low concentration levels. Screen-printed electrodes have been used in quality control in environmental, clinical, food, and agricultural areas [34]. However, according to the best of our knowledge, there are no papers in the literature that report on the application of screen-printed sensors for the determination of DF.

Due to the huge scale of consumption of pharmaceutical preparations, including DF and their negative impact on the environment and consequently on human health, it is necessary to develop new comprehensive methods for their analytical determination in environmental samples directly in the laboratory field. The aim of this work was to present a new voltammetric procedure for the determination of ultratrace concentrations of DF with a screen-printed sensor. 


\section{Materials and Methods}

\subsection{Apparatus}

Voltammetric measurements were performed using a $\mu$ AUTOLAB analyzer (Eco Chemie, Utrecht, The Netherlands) controlled by GPES 4.9 software in a $10 \mathrm{~mL}$ electrochemical cell with a commercially available screen-printed sensor (screen-printed carbon electrode modified with carboxyl functionalized multiwalled carbon nanotubes (SPCE/MWCNTs-COOH); DropSens, Llanera, Spain; Ref. 110CNT). This three-electrode system consisted of a working electrode (screen-printed carbon electrode covered by carboxyl functionalized multiwalled carbon nanotubes with a diameter of $4 \mathrm{~mm}$ ), an auxiliary electrode (SPCE), and a reference electrode (screen-printed silver electrode). In order to characterize the SPCE/MWCNTs-COOH, a commercially available screen-printed carbon electrode (SPCE, DropSens; reference number: C110) was used. The optical profiles and the microscopic images of sensors were recorded using the Contour GT-K1 optical profilometer (Veeco, New York, USA) and a high-resolution scanning electron microscope Quanta 3D FEG (FEI, Hillsboro , USA). Chromatographic analyses were performed on a VWR Hitachi Elite LaChrom HPLC system equipped with a spectrophotometric detector (PDA) and EZChrom Elite software (version 3.3.2 SP2, Merck, Darmstadt, Germany).

\subsection{Reagents}

2-[(2,6-dichlorophenyl)amino]benzeneacetic acid sodium salt (DF, Sigma-Aldrich, Saint Louis, USA) was dissolved in deionized water to prepare a $0.01 \mathrm{~mol} \mathrm{~L}^{-1}$ stock solution of DF. This solution was diluted as required in individual experiments using deionized water. The effects of the type and the $\mathrm{pH}$ of the supporting electrolyte on the DF signal were examined using $0.1 \mathrm{~mol} \mathrm{~L}^{-1}$ solutions of $\mathrm{H}_{2} \mathrm{SO}_{4}, \mathrm{CH}_{3} \mathrm{COOH}, \mathrm{CH}_{3} \mathrm{COONa}+\mathrm{CH}_{3} \mathrm{COOH}$ (NaAc-HAc) with $\mathrm{pH}$ values of $3.5 \pm 0.1,4.0 \pm 0.1$, $4.2 \pm 0.1,4.5 \pm 0.1,5.0 \pm 0.1$ and $5.6 \pm 0.1, \mathrm{~K}_{2} \mathrm{HPO}_{4}+\mathrm{KH}_{2} \mathrm{PO}_{4}$ with a $\mathrm{pH}$ value of $7.0 \pm 0.1,\left(\mathrm{NH}_{4}\right)_{2} \mathrm{SO}_{4}+$ $\mathrm{NH}_{4} \mathrm{OH}$ with a $\mathrm{pH}$ value of $8.3 \pm 0.1, \mathrm{NH}_{4} \mathrm{Cl}+\mathrm{NH}_{4} \mathrm{OH}$ with a $\mathrm{pH}$ value of $10.0 \pm 0.1$, and $\mathrm{NaOH}$ with a $\mathrm{pH}$ value of $13.0 \pm 0.1$ prepared from Sigma-Aldrich reagents. Interferences were tested with the use of standard solutions of $\mathrm{Ni}^{2+}, \mathrm{Fe}^{3+}, \mathrm{Zn}^{2+}, \mathrm{Pb}^{2+}, \mathrm{Sb}^{3+}, \mathrm{Cu}^{2+}, \mathrm{Cd}^{2+}, \mathrm{V}^{5+}$, and $\mathrm{Mo}^{6+}$ (Merck). The influences of organic substances were investigated based on a reagent obtained from Sigma-Aldrich (ibuprofen, caffeine, paracetamol, and humic acid) and Fluka (Triton X-100, sodium dodecyl sulphate (SDS), and cetyltrimethylamonnium bromide (CTAB)). HPLC-grade acetonitrile and trifluoroacetic acids (TFA) were purchased from Merck (Darmstadt, Germany). The solutions were prepared using ultrapurified water (>18 M $\Omega \mathrm{cm}$, Milli-Q system, Millipore, UK).

\subsection{DF Voltammetric Analysis}

Differential-pulse adsorptive stripping voltammetric (DPAdSV) measurements of DF under optimized conditions were carried out in a $0.1 \mathrm{~mol} \mathrm{~L}^{-1} \mathrm{NaAc}-\mathrm{HAc}$ buffer solution with a $\mathrm{pH}$ value of $4.0 \pm 0.1$. An accumulation potential $\left(E_{a c c}\right)$ of $-0.25 \mathrm{~V}$ was applied when stirring the solution for a period of $60 \mathrm{~s}$ (accumulation time was represented by $t_{a c c}$ ). After an equilibrium time of $5 \mathrm{~s}, \mathrm{DPAdSV}$ curves were recorded from -0.25 to $1.5 \mathrm{~V}$ with an amplitude $(A)$ of $125 \mathrm{mV}$, a modulation time $\left(t_{m}\right)$ of $10 \mathrm{~ms}$, and a scan rate $(v)$ of $175 \mathrm{mV} \mathrm{s}^{-1}$. Then, the background curve was subtracted, and the DPAdSV curves were cut in the potential range of $0.4-0.8 \mathrm{~V}$. The DPAdSV curves for each concentration of DF were recorded 3 times, and the average values of peak currents are shown with an SD for $n=3$.

\subsection{DF Chromatographic Analysis}

Chromatographic conditions were based on the literature [35] with a slight modification of the eluent composition. The chromatographic system was as follows: an XB-C18 reversed-phase core-shell column (Kinetex, Phenomenex, Aschaffenburg, Germany) $(25 \mathrm{~cm}$ of length $\times 4.6 \mathrm{~mm}$ of column diameter, particle size: $5 \mu \mathrm{m}$ ) and a mixture of acetonitrile and water with $0.025 \%$ of trifluoroacetic acid $(v / v: 6: 4)$. The flow rate of mobile phase was $1.0 \mathrm{~mL} \mathrm{~min}^{-1}$, and the temperature of thermostat 
was set at $25^{\circ} \mathrm{C}$. Injection volumes were 20 and $80 \mu \mathrm{L}$. All samples were analyzed in triplicate at a wavelength of $276 \mathrm{~nm}$.

\subsection{Real Sample Application}

The voltammetric and chromatographic methods were applied for the determination of DF in Vistula river (Poland) samples stored in sterile, polypropylene containers (Merck), which were collected from two places: at the sewage outlet (sample \#1) and about 5 kilometres from the outflow of sewage (sample \#2). The water samples were filtered using a $0.45 \mu \mathrm{m}$ Millipore membrane and then directly analyzed without performing any special sample pretreatment procedure.

\section{Results and Discussion}

\subsection{Characteristics of SPCE/MWCNTs-COOH Sensors}

In order to understand the use of SPCE/MWCNTs-COOH for the assay of DF, the DPAdSV curves in the DF concentration range of $0.5-200.0 \mathrm{nmol} \mathrm{L}^{-1}$ were recorded in a $0.1 \mathrm{~mol} \mathrm{~L}^{-1} \mathrm{NaAc}-\mathrm{HAc}$ solution with a $\mathrm{pH}$ value of $5.0 \pm 0.1$ at the surface of a bare SPCE and the surface of an SPCE/MWCNTs-COOH. DF showed an oxidation peak at $412 \mathrm{mV}$ with the bare SPCE. At the SPCE/MWCNTs-COOH, the oxidation peak appeared at $377 \mathrm{mV}$ with considerable enhancement in peak current (Figure 1). The oxidation current responses were found to be proportional to the DF concentrations over the ranges of 1.0-200.0 nmol L-1 (correlation coefficient $r=0.9997)$ and $0.5-200.0 \mathrm{nmol} \mathrm{L}^{-1}(\mathrm{r}=0.9971)$ at the surfaces of the bare SPCE and the SPCE/MWCNTs-COOH, respectively. The sensitivity values of DF determination at the surfaces of the bare SPCE and the SPCE/MWCNTs-COOH are equal to 0.019 and $0.040 \mu \mathrm{A} / \mathrm{nmol} \mathrm{L}^{-1}$, respectively. Compared with the SPCE, the commercially available SPCE/MWCNTs-COOH provided a higher sensitivity and a wider linear range, which was connected with the developed active surface of the sensor modified with carboxyl functionalized carbon nanotubes.

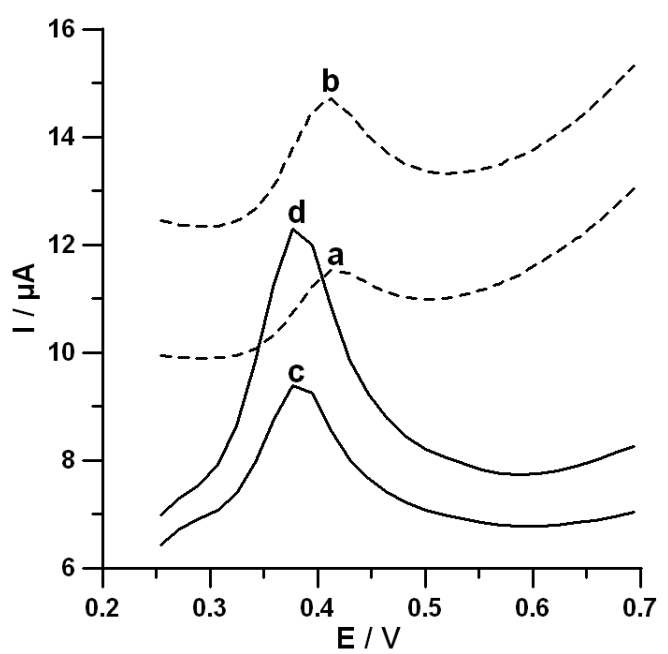

Figure 1. Differential-pulse adsorptive stripping voltammetric (DPAdSV) curves of diclofenac (DF) with different concentrations in a $0.1 \mathrm{~mol} \mathrm{~L}^{-1} \mathrm{NaAc}-\mathrm{HAc}$ solution with a $\mathrm{pH}$ value of $5.0 \pm 0.1$ at the surface of a bare screen-printed carbon electrode (SPCE) $(a, b)$ and the surface of a screen-printed carbon electrode modified with multiwalled carbon nanotubes (SPCE/MWCNTs-COOH) (c,d). (a) and (c) are for the DF concentration of $0.05 \mu \mathrm{mol} \mathrm{L}{ }^{-1}$. (b) and (d) are for the DF concentration of $0.1 \mu \mathrm{mol} \mathrm{L}-1$. The DPAdSV parameters: accumulation potential $\left(E_{a c c}\right)$ of $-0.5 \mathrm{~V}$, accumulation time $\left(t_{a c c}\right)$ of $30 \mathrm{~s}$, amplitude $(A)$ of $100 \mathrm{mV}$, modulation time $\left(t_{m}\right)$ of $40 \mathrm{~ms}$, and scan rate $(v)$ of $175 \mathrm{mV} \mathrm{s}^{-1}$.

The morphological studies of SPCE and SPCE/MWCNTs-COOH surfaces were performed using an optical profilometer and a scanning electron microscope. As illustrated in Figure 2A, the modification of the SPCE surface with carboxyl functionalized MWCNTs had a slight impact on the increase of 
surface roughness $\left(\mathrm{R}_{\mathrm{a}}: 1.12\right.$ and $1.30 \mu \mathrm{m}$ for the SPCE and the SPCE/MWCNTs-COOH, respectively). This confirmed that the whole SPCE surface was covered with a thin layer of carboxyl functionalized MWCNTs, which is also visible in the SEM images (Figure 2B). The carboxyl functionalized MWCNTs were dispersed onto the SPCE without aggregation with special three-dimensional structures and smooth surface [11].
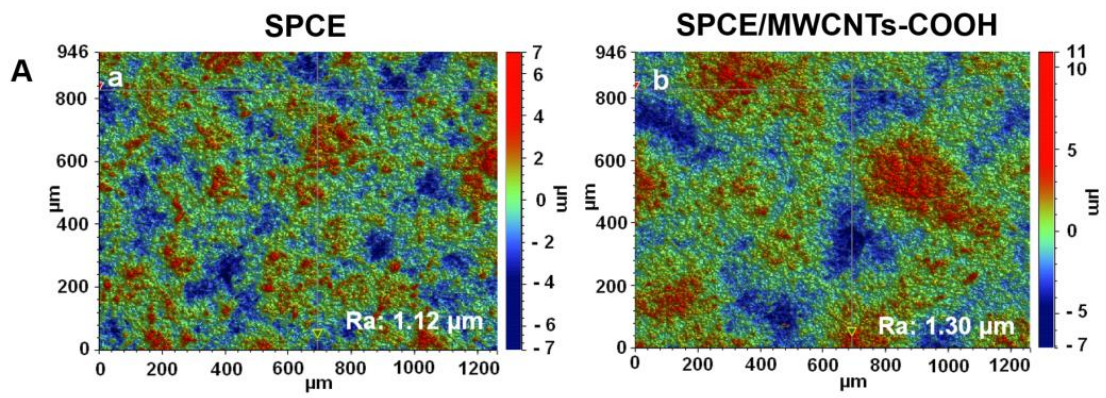

B
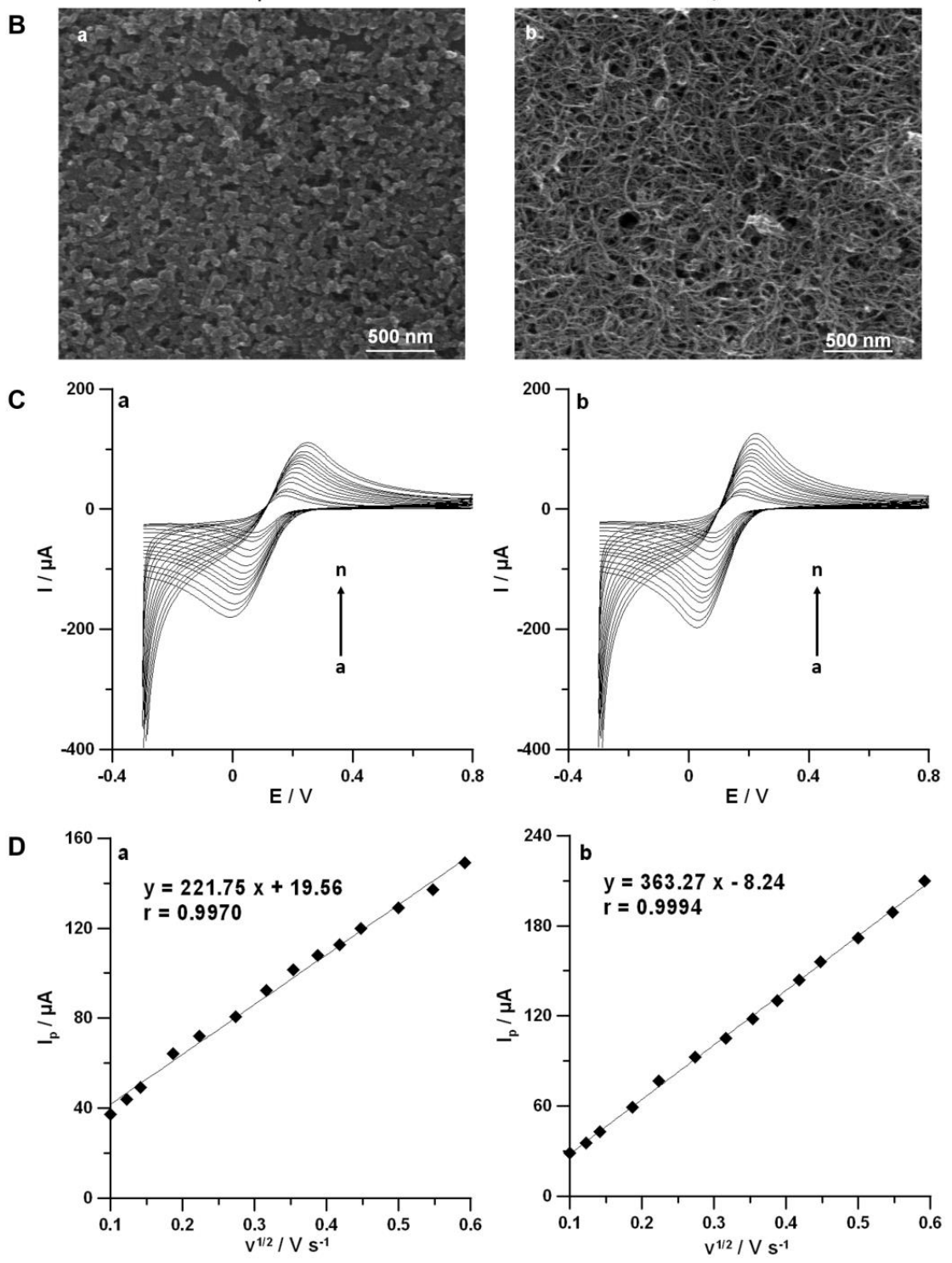

Figure 2. (A) Optical profiles. (B) SEM images of the SPCE (a) and the SPCE/MWCNTs-COOH (b). (C) CV curves recorded at the surfaces of the SPCE (a) and the SPCE/MWCNTs-COOH (b) in a solution of $0.1 \mathrm{~mol} \mathrm{~L}^{-1} \mathrm{KCl}$ containing $5.0 \mathrm{mmol} \mathrm{L}^{-1} \mathrm{~K}_{3}\left[\mathrm{Fe}(\mathrm{CN})_{6}\right]$ at a $v$ range of $5-500 \mathrm{mV} \mathrm{s}^{-1}$. (D) Dependences between $I_{p}$ and $v^{1 / 2}$ for the SPCE (a) and the SPCE/MWCNTs (b). 
The electrochemical properties of the SPCE and the SPCE/MWCNTs-COOH were also tested using cyclic voltammetry $(\mathrm{CV})$ in a solution of $0.1 \mathrm{~mol} \mathrm{~L}^{-1} \mathrm{KCl}$ and $5.0 \mathrm{mmol} \mathrm{L}^{-1} \mathrm{~K}_{3}\left[\mathrm{Fe}(\mathrm{CN})_{6}\right]$. Figure $2 \mathrm{C}$ illustrates the $C V$ curves recorded with both electrodes at scan rates of $5-500 \mathrm{mV} \mathrm{s}^{-1}$, and Figure $2 \mathrm{D}$ shows the dependences between the anodic peak current $\left(I_{p}\right)$ and the square root of scan rate $\left(v^{1 / 2}\right)$. Based on these results, peak-to-peak separations $(\Delta E)$ and relative peak separations $\left(\chi^{0}\right)$ for a scan rate of $175 \mathrm{mV} \mathrm{s}^{-1}$ and active surface areas $\left(A_{s}\right)$ based on the entire range of scan rates were calculated [36]. The results were summarized in Table 1 and indicated the improvement of the reversibility process and electron transfer kinetics by the modification of the SPCE surface with carboxyl functionalized MWCNTs. Moreover, the covering surface with carboxyl functionalized MWCNTs increased the number of active centers, which translated to the enhancement in DF peak current.

Table 1. Electrochemical characteristics of the SPCE and the SPCE/MWCNTs-COOH using cyclic voltammetry $(\mathrm{CV})$ in a solution of $0.1 \mathrm{~mol} \mathrm{~L}^{-1} \mathrm{KCl}$ and $5.0 \mathrm{mmol} \mathrm{L}^{-1} \mathrm{~K}_{3}\left[\mathrm{Fe}(\mathrm{CN})_{6}\right]$.

\begin{tabular}{ccc}
\hline Calculated parameter & SPCE & SPCE/MWCNTs-COOH \\
\hline$\Delta E$ for $v$ of $175 \mathrm{mV} \mathrm{s}^{-1}$ & $189.0 \pm 1.9 \mathrm{mV}(\mathrm{n}=3)$ & $149.0 \pm 1.5 \mathrm{mV}(\mathrm{n}=3)$ \\
$\chi^{0}$ for $v$ of $175 \mathrm{mV} \mathrm{s}^{-1}$ & $3.26 \pm 0.031(\mathrm{n}=3)$ & $2.57 \pm 0.025(\mathrm{n}=3)$ \\
$A_{s}$ for $v$ of $5-500 \mathrm{mV} \mathrm{s}^{-1}$ & $0.061 \pm 0.00058 \mathrm{~cm}^{2}(\mathrm{n}=3)$ & $0.10 \pm 0.00097 \mathrm{~cm}^{2}(\mathrm{n}=3)$ \\
\hline
\end{tabular}

The above described results confirmed the benefits of using the SPCE/MWCNTs-COOH. Therefore, in further experiments, this kind of modified sensor was used for the analysis of DF.

\subsection{Optimization of Measurements Solution Composition}

The effects of the type and the $\mathrm{pH}$ of the supporting electrolyte on the voltammetric responses of 0.05 and $0.1 \mu \mathrm{mol} \mathrm{L}{ }^{-1}$ DF were examined using a $0.1 \mathrm{~mol} \mathrm{~L}^{-1}$ solution of $\mathrm{H}_{2} \mathrm{SO}_{4}, \mathrm{CH}_{3} \mathrm{COOH}$ and $\mathrm{CH}_{3} \mathrm{COONa}+\mathrm{CH}_{3} \mathrm{COOH}(\mathrm{NaAc}-\mathrm{HAc}$ ) with $\mathrm{pH}$ values of $3.5 \pm 0.1,4.0 \pm 0.1,4.2 \pm 0.1,4.5 \pm 0.1$, $5.0 \pm 0.1$, and $5.6 \pm 0.1, \mathrm{~K}_{2} \mathrm{HPO}_{4}+\mathrm{KH}_{2} \mathrm{PO}_{4}$ with a $\mathrm{pH}$ value of $7.0 \pm 0.1,\left(\mathrm{NH}_{4}\right)_{2} \mathrm{SO}_{4}+\mathrm{NH}_{4} \mathrm{OH}$ with a $\mathrm{pH}$ value $8.3 \pm 0.1, \mathrm{NH}_{4} \mathrm{Cl}+\mathrm{NH}_{4} \mathrm{OH}$ with a $\mathrm{pH}$ value of $10.0 \pm 0.1$, and $\mathrm{NaOH}$ with a $\mathrm{pH}$ value of $13.0 \pm 0.1$; the corresponding data are listed in Figure 3A. The value of the oxidation peak current of DF increased with the increase of $\mathrm{pH}$ value of the solution up to $4.0 \pm 0.1$ for both studied concentrations of DF. There was no electrochemical response of $\mathrm{DF}$ in alkaline media at $\mathrm{pH} \geq 10.0 \pm 0.1$ lacking the presence of enough protons. It was connected with two species of DF (neutral and anionic species), of which the existence depended on $\mathrm{pH}$ values. The literature reports that DF presents a $\mathrm{pK}_{\mathrm{a}}$ of 4.15, so for $\mathrm{pH}$ smaller than 4.15 the neutral species predominates, whereas at a greater $\mathrm{pH}$ the anionic species predominates [37]. Considering the obtained data, the NaAc-HAc buffer solution with a $\mathrm{pH}$ value of $4.0 \pm 0.1$ is most suitable for the DF determination.

Furthermore, its concentration was evaluated from 0.05 to $0.5 \mathrm{~mol} \mathrm{~L}^{-1}$ (Figure 3B). The highest values of DF $\left(0.05\right.$ and $\left.0.1 \mu \mathrm{mol} \mathrm{L}{ }^{-1}\right)$ signals were attained at a $0.1 \mathrm{~mol} \mathrm{~L}^{-1}$ concentration of the NaAc-HAc buffer solution with a $\mathrm{pH}$ value of $4.0 \pm 0.1$; hence, it was adopted for subsequent experiments.

\section{3. $\mathrm{CV}$ Behaviors of DF with the SPCE/MWCNTs-COOH}

$\mathrm{CV}$ curves (first and second cycles) were recorded in the $0.1 \mathrm{~mol} \mathrm{~L}^{-1} \mathrm{NaAc}-\mathrm{HAc}$ buffer solution with a $\mathrm{pH}$ value of $4.0 \pm 0.1$ containing $1.0 \mu \mathrm{mol} \mathrm{L}^{-1} \mathrm{DF}$ using $v$ equal to $175 \mathrm{mV} \mathrm{s}^{-1}$ (Figure $4 \mathrm{~A}$ ). $\mathrm{DF}$ was irreversibly oxidized, giving rise to an oxidation peak at a potential of $555 \mathrm{mV}$, when the sweep was initiated in the positive direction. In the reverse sweep, two cathodic peaks at potential values of -10 and $275 \mathrm{mV}$ were visible, which formed reversible couples with anodic peaks (102 and $307 \mathrm{mV}$ ) observed in the second cycle towards positive potentials. The reversible couples can be created at less positive potentials due to the formation of electrochemically active oxidation products of DF [11,28]. In contrast to the work of Yang et al. [17], the reduction of effective reaction sites at the surface of the SPCE/MWCNTs-COOH by the adsorption of the reaction products of DF was not observed. The oxidation peak currents of DF in the first and second cycles were similar (curves b and $c$ in Figure 4A). 
Therefore, the regeneration of electrode surface in an additional solution was not required [11]. Further research focused on the DF oxidation peak at a potential of $555 \mathrm{mV}$ with the highest current, which was characterized by the linear increase in the peak current as the concentration increased.

Valuable information with regard to the nature and the oxidation mechanism of DF at the SPCE/MWCNTs-COOH surface could be obtained by recording CV curves at different values of scan rates. Therefore, the electrochemical behaviors of $1.0 \mu \mathrm{mol} \mathrm{L}^{-1} \mathrm{DF}$ in the $0.1 \mathrm{~mol} \mathrm{~L}^{-1} \mathrm{NaAc}-\mathrm{HAc}$ buffer solution with a $\mathrm{pH}$ value of $4.0 \pm 0.1$ for $v$ equal to $5-250 \mathrm{mV} \mathrm{s}^{-1}$ were observed. Figure $4 \mathrm{~B}$ shows the CV curves for the selected $v$ of 50,100 , and $175 \mathrm{mV} \mathrm{s}^{-1}$. The oxidation peak potential shifted toward more positive values with the increase of scan rate, which confirmed that DF was irreversibly oxidized. The linear relationship between the DF peak current (Ip) and the square root of scan rate $\left(v^{1 / 2}\right)$ (Figure $\left.4 \mathrm{C}, \mathrm{r}=0.9934\right)$ indicated that the oxidation process of DF was controlled by diffusion at the surface of the SPCE/MWCNTs-COOH. However, the slope of 0.69 observed in the plot of $\log I p$ vs. $\log v$ (Figure 4D) indicated that this process was not purely diffusion- or adsorption-controlled [38]. Moreover, with the slope of the peak potential (Ep) vs. $\log (v)$ plot (Figure 4E) using the Laviron's equation [39], the number of electrons involved in the DF oxidation process was calculated. The value determined was equal to 1.51, which proved that two electrons were involved in this process. These results are consistent with the literature data [28,40]. Madsen et al. [40] and Gayal et al. [28] proposed that DF is oxidized to 5-hydrohydiclofenac by losses of $2 \mathrm{e}^{-}$and $2 \mathrm{H}^{+}$according to the overall scheme (Figure $4 \mathrm{~F}$ ).
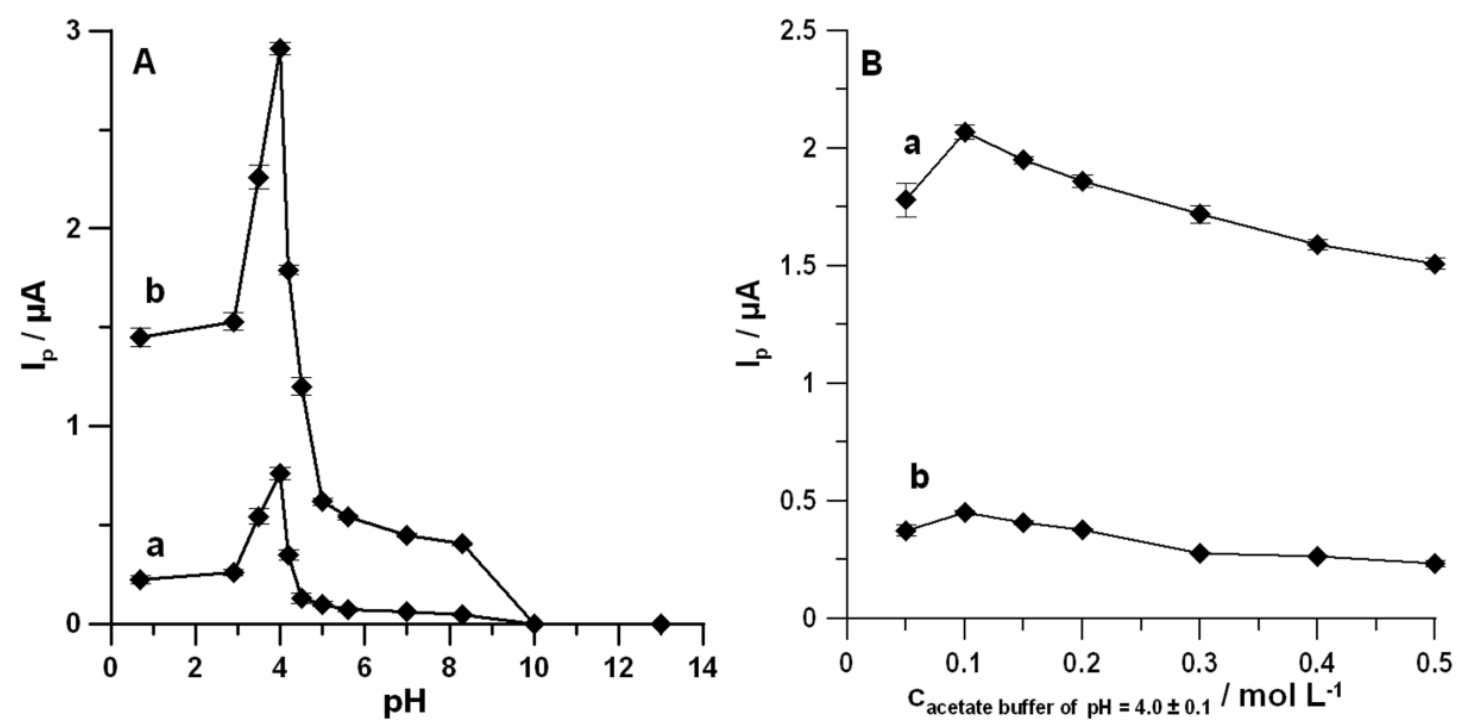

Figure 3. Effects of $\mathrm{pH}$ value (A) and concentration of the $\mathrm{NaAc}-\mathrm{HAc}$ buffer solution with a $\mathrm{pH}$ value of $4.0 \pm 0.1$ (B) on DF current response. (a) and (b) in (A) are for the DF concentration of 0.05 and $0.1 \mu \mathrm{mol} \mathrm{L}{ }^{-1}$, respectively. (a) and (b) in (B) are for the DF concentration of 0.05 and $0.1 \mu \mathrm{mol} \mathrm{L}-1$, respectively. Other parameters are the same as in Figure 1. 

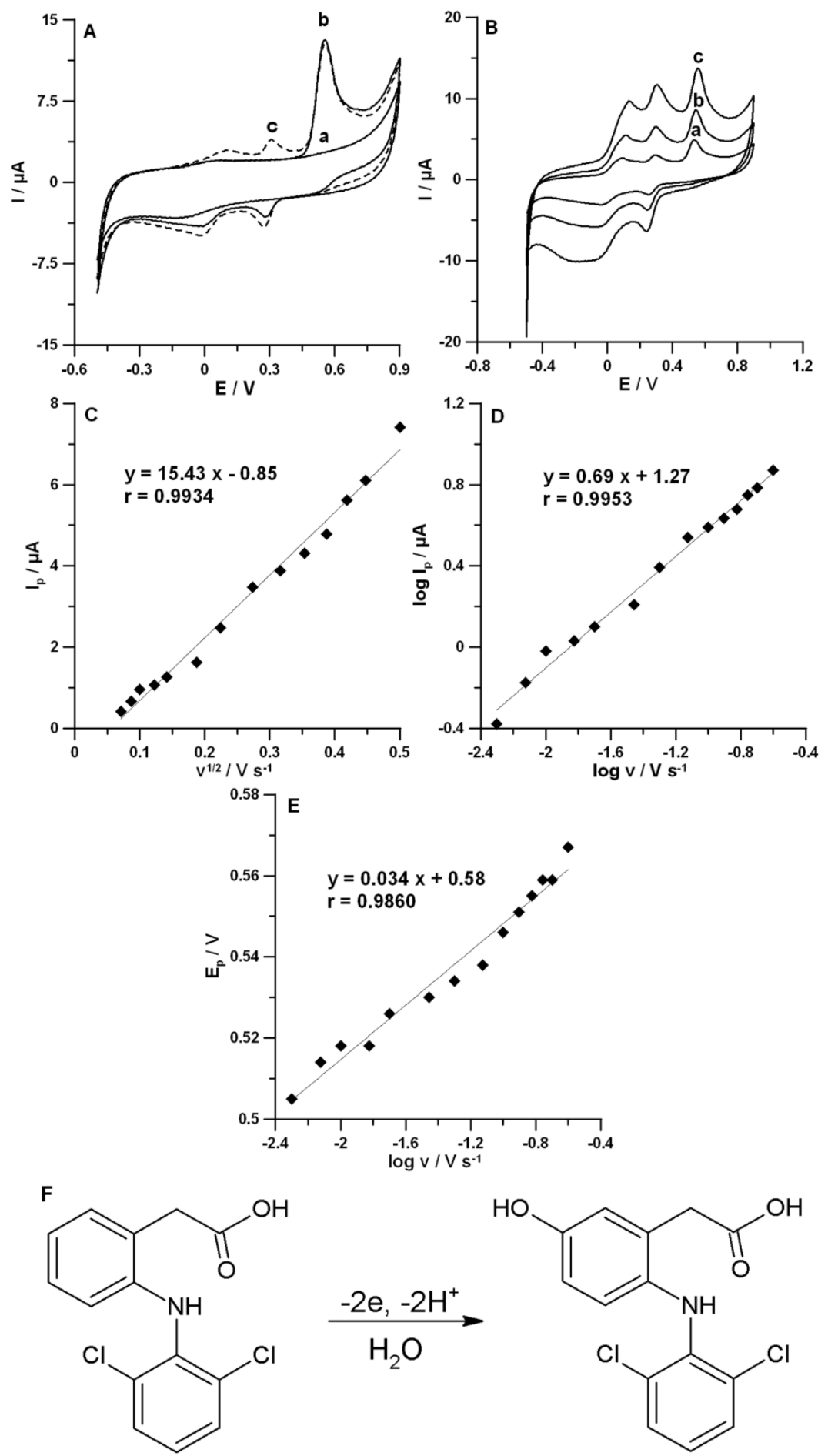<smiles>O=C(O)Cc1cc(O)ccc1Nc1c(Cl)cccc1Cl</smiles>

Figure 4. (A) CV curves recorded in the $0.1 \mathrm{~mol} \mathrm{~L}^{-1} \mathrm{NaAc}-\mathrm{HAc}$ buffer solution with a $\mathrm{pH}$ value of $4.0 \pm 0.1$ at $v$ equal to $175 \mathrm{mV} \mathrm{s}^{-1}$. Curves $(\mathrm{a}-\mathrm{C})$ represent $\mathrm{CV}$ curves in the solution without $\mathrm{DF}$ and with $1.0 \mu \mathrm{mol} \mathrm{L}{ }^{-1} \mathrm{DF}$ for the first cycle and the second cycle, respectively. (B) CV curves recorded in the $0.1 \mathrm{~mol} \mathrm{~L}^{-1} \mathrm{NaAc}-\mathrm{HAc}$ buffer solution with a $\mathrm{pH}$ value of $4.0 \pm 0.1$ containing $1.0 \mu \mathrm{mol} \mathrm{L}-1 \mathrm{DF}$ at different $v$ values. Curves (a-c) represent CV curves at $v$ equal to 50,100 , and $175 \mathrm{mV} \mathrm{s}^{-1}$, respectively. The dependences between $I p$ and $v^{1 / 2}(\mathbf{C}), \log I p$ and $\log v(\mathbf{D})$, and $E_{p}$ and $\log v(\mathbf{E})$ for $v$ from 5 to $250 \mathrm{mV} \mathrm{s}^{-1}$. (F) Oxidation mechanism of DF 


\subsection{Optimization of DPAdSV Parameters}

In order to find the optimum conditions for the DF determination at the surface of the SPCE/MWCNTs-COOH, the influences of various DPAdSV parameters including accumulation potential $\left(E_{a c c}\right)$, accumulation time $\left(t_{a c c}\right)$, amplitude $(A)$, modulation time $\left(t_{m}\right)$, and scan rate $(v)$ on the DF oxidation peak current $\left(0.01\right.$ and $\left.0.05 \mu \mathrm{mol} \mathrm{L}{ }^{-1}\right)$ were studied.

The effects of $E_{a c c}$ and $t_{a c c}$ were tested, because the oxidation process of DF at the SPCE/MWCNTs$\mathrm{COOH}$ surface was not purely diffusion- or adsorption-controlled. The $E_{a c c}$ was varied in the range of $-1.25-0.25 \mathrm{~V}$, and $t_{a c c}$ was equal to $30 \mathrm{~s}$. Figure $5 \mathrm{~A}$ shows that for both studied concentrations of DF, the maximum values of peak current were achieved at $E_{a c c}$ of $-0.25 \mathrm{~V}$. Then, at this potential value, $t_{a c c}$ was changed from 0 to $300 \mathrm{~s}$. As can be seen in Figure 5B, taking into account the highest peak currents of DF, $t_{a c c}$ of $60 \mathrm{~s}$ can be considered as an optimum condition.
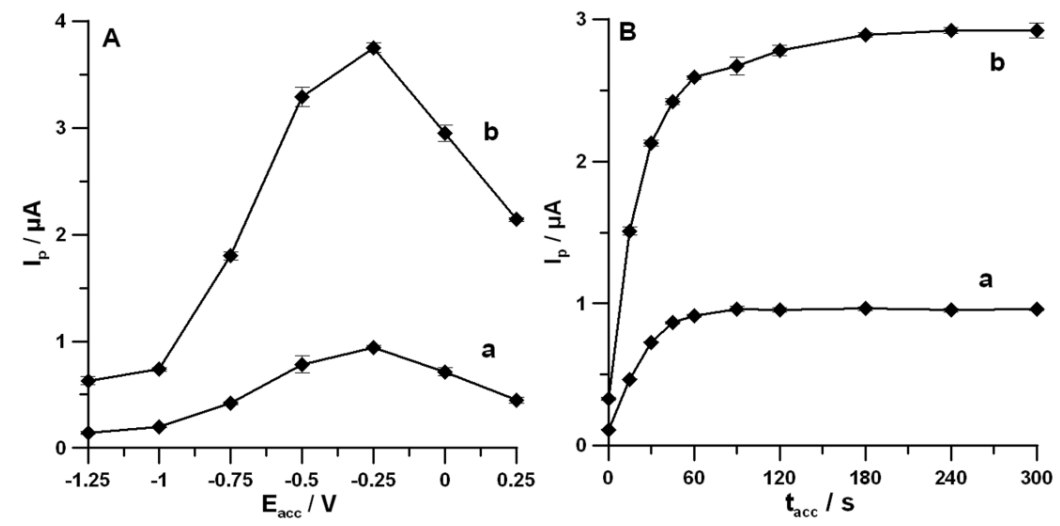

Figure 5. Effects of $E_{a c c}(\mathbf{A})$ and $t_{a c c}(\mathbf{B})$ on DF current response. $(\mathrm{a}, \mathrm{b})$ in $(\mathbf{A})$ represent the responses for DF concentrations of 0.01 and $0.05 \mu \mathrm{mol} \mathrm{L}{ }^{-1}$, respectively. $(a, b)$ in $(\mathbf{B})$ represent the responses for DF concentrations of 0.01 and $0.05 \mu \mathrm{mol} \mathrm{L}{ }^{-1}$, respectively. The DPAdSV parameters in (A) are $\mathrm{t}_{\mathrm{acc}}$ of $30 \mathrm{~s}$, $A$ of $100 \mathrm{mV}, t_{m}$ of $40 \mathrm{~ms}$, and $v$ of $175 \mathrm{mV} \mathrm{s}^{-1}$; the DPAdSV parameters in (B) are $E_{a c c}$ of $-0.25 \mathrm{~V}, A$ of $100 \mathrm{mV}, t_{m}$ of $40 \mathrm{~ms}$, and $v$ of $175 \mathrm{mV} \mathrm{s}^{-1}$.

Moreover, $A$ was investigated from 25 to $150 \mathrm{mV}$ (for $v$ of $175 \mathrm{mV} \mathrm{s}^{-1}$ and $t_{m}$ of $40 \mathrm{~ms}$ ). The highest signals of DF for both studied concentrations were recorded at $A$ equal to $125 \mathrm{mV}$ (Figure 6A). Then, the effect of $v\left(50-200 \mathrm{mV} \mathrm{s}^{-1}\right)$ on DF peak current at the constant values of $A(125 \mathrm{mV})$ and $t_{m}(40 \mathrm{~ms})$ was tested. Figure $6 \mathrm{~B}$ shows the maximum values of DF peak current at vof $175 \mathrm{mV} \mathrm{s}^{-1}$. Furthermore, $t_{m}$ was varied from 2 to $60 \mathrm{~ms}$ (for $A$ of $125 \mathrm{mV}$ and $v$ of $175 \mathrm{mV} \mathrm{s}^{-1}$ ). It was found that, for $t_{m}$ of $10 \mathrm{~ms}$, the highest signals of DF were obtained (Figure 6C).
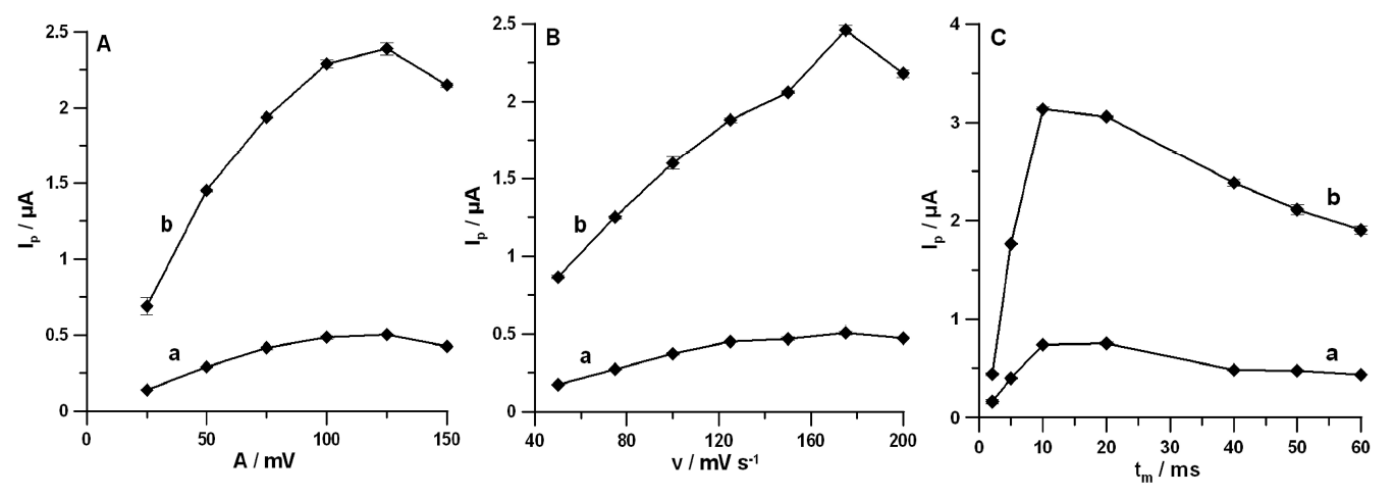

Figure 6. Effects of $A(\mathbf{A}), v(\mathbf{B})$, and $t_{m}(\mathbf{C})$ on DF current response. Curves $(\mathrm{a}, \mathrm{b})$ are for 0.01 and $0.05 \mu \mathrm{mol} \mathrm{L}-1 \mathrm{DF}$, respectively. The DPAdSV parameters: (A) $E_{a c c}$ of $-0.25 \mathrm{~V}, t_{a c c}$ of $60 \mathrm{~s}, v$ of $175 \mathrm{mV} \mathrm{s}^{-1}$ and $t_{m}$ of $40 \mathrm{~ms}$; (B) A of $125 \mathrm{mV}$ and $\mathrm{t}_{\mathrm{m}}$ of $40 \mathrm{~ms}$; and (C) $A$ of $125 \mathrm{mV}$ and $v$ of $175 \mathrm{mV} \mathrm{s}^{-1}$. 


\subsection{Analytical Characteristics}

Under optimized conditions (see the DF voltammetric analysis section), the oxidation current responses were found to be proportional to the DF concentrations over the range of $0.1-10.0 \mathrm{nmol} \mathrm{L}^{-1}$. The corresponding results are shown in Figure 7 and Table 2. The sensitivity of DF determination at the SPCE/MWCNTs-COOH was equal to $0.18 \pm 0.0070 \mu \mathrm{A} / \mathrm{nmol} \mathrm{L}^{-1}$. The LOD and the limit of quantification (LOQ) were 0.028 and $0.094 \mathrm{nmol} \mathrm{L}^{-1}$, respectively. The LOD and LOQ values demonstrated that the SPCE/MWCNTs-COOH can be used for analysis of environmental water samples, in which the $\mathrm{DF}$ concentration is in the range of $0.037-14.0 \mathrm{nmol} \mathrm{L}^{-1}[2,3]$. It should be clearly emphasized that the SPCE/MWCNTs-COOH allowed obtaining the lowest LOD value compared to all other electrochemical sensors (see Table 3). Moreover, the obtained LOD was significantly lower than those obtained by other techniques applied for DF determination without sample pretreatment steps [8,9].

Moreover, the intra-day and inter-day precisions were verified for the determination of $10.0 \mathrm{nmol} \mathrm{L}^{-1} \mathrm{DF}$ with 10 replicates and replicated on five different days, respectively. The results of the intra-day and inter-day precisions were $0.7 \%$ and $2.1 \%$, respectively, indicating the satisfactory precious repeatability of the signal at the SPCE/MWCNTs-COOH surface. The reproducibility of the SPCE/MWCNTs-COOH was estimated by recording DPAdSV curves in the solution containing $10.0 \mathrm{nmol} \mathrm{L}{ }^{-1} \mathrm{DF}$ using three commercially available electrodes. The relative standard deviation (RSD) was calculated as $2.9 \%(n=9)$, confirming the acceptable reproducibility of the proposed sensor.
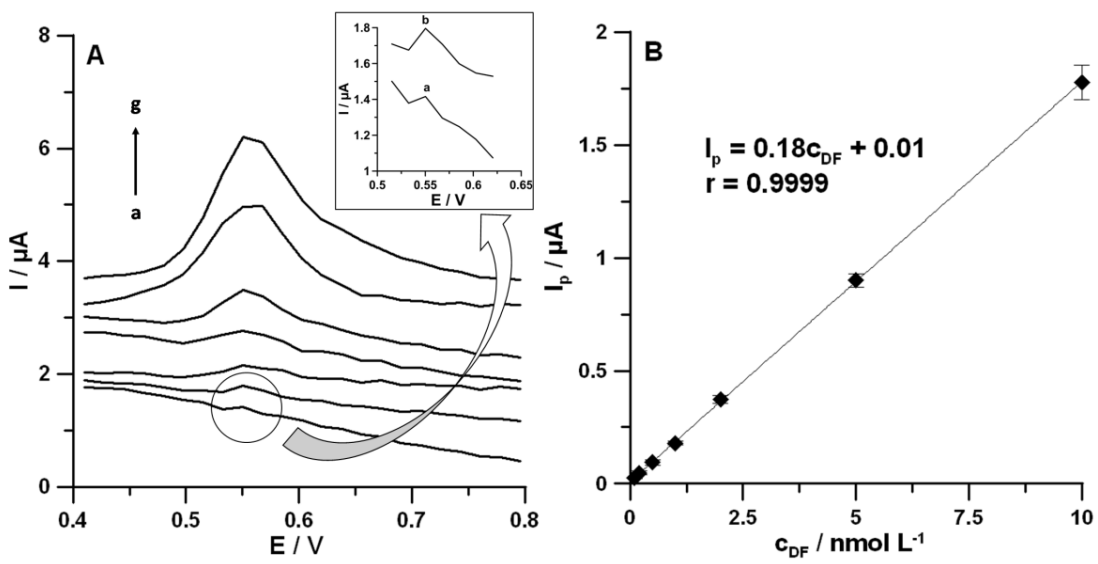

Figure 7. (A) DPAdSV curves recorded at the surface of the SPCE/MWCNTs-COOH in the NaAc-HAc buffer solution with a $\mathrm{pH}$ value of $4.0 \pm 0.1$ containing increasing concentrations of DF: (a) 0.1 , (b) 0.2 , (c) 0.5, (d) 1.0, (e) 2.0, (f) 5.0, and (g) $10.0 \mathrm{nmol} \mathrm{L}^{-1}$. (B) Calibration graph of DF. The DPAdSV parameters: $E_{a c c}$ of $-0.25 \mathrm{~V}, t_{a c c}$ of $60 \mathrm{~s}, A$ of $125 \mathrm{mV}, t_{m}$ of $10 \mathrm{~ms}$, and $v$ of $175 \mathrm{mV} \mathrm{s}^{-1}$.

Table 2. Characteristics of the calibration plot of DF obtained at the SPCE/MWCNTs-COOH surface.

\begin{tabular}{cc}
\hline Parameter & DPAdSV \\
\hline Linear range $\left(\mathrm{nmol} \mathrm{L}^{-1}\right)$ & $0.1-10.0$ \\
Accumulation time $(\mathrm{s})$ & 60 \\
Slope $(\mathrm{b}) \pm \mathrm{SD}_{\mathrm{b}}(\mathrm{n}=3)\left(\mu \mathrm{A} / \mathrm{nmol} \mathrm{L}^{-1}\right)$ & $0.18 \pm 0.0070$ \\
Intercept $(\mathrm{a}) \pm \mathrm{SD}_{\mathrm{a}}(\mathrm{n}=3)(\mu \mathrm{A})$ & $0.010 \pm 0.0017$ \\
Correlation coefficient $(\mathrm{r})$ & 0.028 \\
Limit of detection $\left.(\mathrm{LOD} ; \mathrm{nmol} \mathrm{L})^{-1}\right)$ & 0.094 \\
Limit of quantification $\left(\mathrm{LOQ} ; \mathrm{nmol} \mathrm{L}{ }^{-1}\right)$ & 0.7 \\
Intra-day precision $(\mathrm{RSD}, \mathrm{n}=10)(\%)$ & 2.1 \\
Inter-day precision $(\mathrm{RSD}, \mathrm{n}=15)(\%)$ & 2.9 \\
Reproducibility $(\mathrm{RSD}, \mathrm{n}=9)(\%)$ &
\end{tabular}

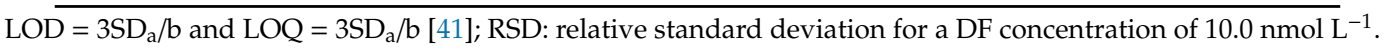


Table 3. Comparison of electrochemical methods for the determination of DF.

\begin{tabular}{|c|c|c|c|c|c|}
\hline Electrode & Method & Linear Range $\left(\mathrm{mol} \mathrm{L}^{-1}\right)$ & Detection Limit $\left(\mathrm{mol} \mathrm{L}^{-1}\right)$ & Application & Ref. \\
\hline n-GCE & $\mathrm{CV}$ & $2.0 \times 10^{-4}-1.5 \times 10^{-3}$ & $2.8 \times 10^{-5}$ & pharmaceutical formulations & [10] \\
\hline NiNPs/ERGO/GCE & SWV & $2.5 \times 10^{-7}-1.3 \times 10^{-4}$ & $9.0 \times 10^{-8}$ & $\begin{array}{l}\text { pharmaceutical formulations, } \\
\text { urine samples }\end{array}$ & [1] \\
\hline AuNP/MWCNT/GCE & SWV & $3.0 \times 10^{-8}-2.0 \times 10^{-4}$ & $2.0 \times 10^{-8}$ & $\begin{array}{c}\text { pharmaceutical formulations, } \\
\text { urine samples }\end{array}$ & [11] \\
\hline $\begin{array}{c}\mathrm{MWCNTs} / \\
\mathrm{Cu}(\mathrm{OH})_{2} / \mathrm{IL} / \mathrm{GCE}\end{array}$ & DPV & $1.8 \times 10^{-7}-1.2 \times 10^{-4}$ & $4.0 \times 10^{-8}$ & pharmaceutical formulations & [12] \\
\hline MWCNT-IL/CCE & DPV & $5.0 \times 10^{-8}-2.0 \times 10^{-5}$ & $2.7 \times 10^{-8}$ & blood plasma samples & [13] \\
\hline GO-COOH/GCE & LSV & $1.2 \times 10^{-6}-4.0 \times 10^{-4}$ & $9.0 \times 10^{-8}$ & $\begin{array}{l}\text { urine samples, } \\
\text { blood serum samples }\end{array}$ & [14] \\
\hline $\begin{array}{l}\text { GCE/Amino-AT } \\
\text { GCE/APTES-Amino-AT-Silica }\end{array}$ & SWV & $3.0 \times 10^{-7}-2.0 \times 10^{-5}$ & $\begin{array}{l}2.0 \times 10^{-7} \\
5.3 \times 10^{-8}\end{array}$ & $\begin{array}{l}\text { pharmaceutical formulations, } \\
\text { spiked water samples }\end{array}$ & [15] \\
\hline PDDA-GR/GCE & DPV & $1.0 \times 10^{-5}-1.0 \times 10^{-4}$ & $6.1 \times 10^{-7}$ & $\begin{array}{l}\text { pharmaceutical formulations, } \\
\text { spiked lake water samples }\end{array}$ & [16] \\
\hline MWNTs-DHP/GCE & $\mathrm{CV}$ & $\begin{array}{l}1.7 \times 10^{-7}-2.5 \times 10^{-6} \\
2.5 \times 10^{-6}-7.5 \times 10^{-5}\end{array}$ & $8.0 \times 10^{-8}$ & pharmaceutical formulations & [17] \\
\hline DBA/GCE & $\mathrm{CV}$ & $1.0 \times 10^{-5}-1.0 \times 10^{-3}$ & $2.7 \times 10^{-7}$ & blood serum samples & [18] \\
\hline CPE & SWV & $1.0 \times 10^{-6}-1.0 \times 10^{-5}$ & $2.0 \times 10^{-7}$ & spiked model water samples & [19] \\
\hline MWCNTs/CoHCF/IL/PE & DPV & $1.0 \times 10^{-3}-1.0 \times 10^{-1}$ & $3.0 \times 10^{-4}$ & $\begin{array}{l}\text { pharmaceutical formulations, } \\
\text { urine samples }\end{array}$ & [20] \\
\hline $\mathrm{Fe}_{3} \mathrm{O}_{4} @ \mathrm{SiO}_{2} / \mathrm{MWCNTs-CPE}$ & SWV & $5.0 \times 10^{-7}-1.0 \times 10^{-4}$ & $4.0 \times 10^{-8}$ & $\begin{array}{l}\text { pharmaceutical formulations, } \\
\text { blood serum samples }\end{array}$ & [21] \\
\hline VFMCNTPE & SWV & $2.5 \times 10^{-6}-6.0 \times 10^{-4}$ & $2.0 \times 10^{-6}$ & $\begin{array}{c}\text { pharmaceutical formulations, } \\
\text { urine samples }\end{array}$ & [22] \\
\hline IL/CNTPE & DPV & $5.0 \times 10^{-7}-3.0 \times 10^{-4}$ & $2.0 \times 10^{-7}$ & $\begin{array}{l}\text { pharmaceutical formulations, } \\
\text { urine samples }\end{array}$ & [23] \\
\hline IL/CNTPE & SWV & $3.0 \times 10^{-7}-7.5 \times 10^{-4}$ & $9.0 \times 10^{-8}$ & $\begin{array}{c}\text { pharmaceutical formulations, } \\
\text { urine samples }\end{array}$ & [24] \\
\hline Silica NPs-CPE & DPV & $1.0 \times 10^{-7}-5.0 \times 10^{-4}$ & $4.6 \times 10^{-8}$ & pharmaceutical formulations & [25] \\
\hline TCPE & DPV & $1.0 \times 10^{-5}-1.4 \times 10^{-4}$ & $3.3 \times 10^{-6}$ & $\begin{array}{c}\text { pharmaceutical formulations, } \\
\text { urine samples }\end{array}$ & [26] \\
\hline PTFE-G; EG; E-CB & DPV & $6.0 \times 10^{-8}-1.0 \times 10^{-6}$ & $5.0 \times 10^{-8}$ & pharmaceutical formulations & [27] \\
\hline EPPG & SWV & $1.0 \times 10^{-8}-1.0 \times 10^{-6}$ & $6.2 \times 10^{-9}$ & $\begin{array}{l}\text { pharmaceutical formulations, } \\
\text { urine samples }\end{array}$ & [28] \\
\hline CuZEGE & CV, DPV & $2.0 \times 10^{-5}-3.0 \times 10^{-7}$ & $5.0 \times 10^{-8}$ & - & [29] \\
\hline MWCNT-IL/CCE & DPV & $5.0 \times 10^{-8}-5.0 \times 10^{-5}$ & $1.8 \times 10^{-8}$ & $\begin{array}{l}\text { pharmaceutical formulations, } \\
\text { blood plasma samples }\end{array}$ & [30] \\
\hline BDDE & DPV & $3.1 \times 10^{-7}-3.1 \times 10^{-5}$ & $3.0 \times 10^{-8}$ & spiked tap water samples & [31] \\
\hline PtDE & DPV & $5.0 \times 10^{-6}-5.9 \times 10^{-5}$ & $1.0 \times 10^{-6}$ & $\begin{array}{l}\text { pharmaceutical formulations, } \\
\text { blood serum samples }\end{array}$ & [32] \\
\hline PtDE & SWV & $5.1 \times 10^{-6}-5.9 \times 10^{-5}$ & $1.7 \times 10^{-6}$ & $\begin{array}{l}\text { pharmaceutical preparations, } \\
\text { blood serum samples }\end{array}$ & [33] \\
\hline SPCE/MWCNTs-COOH & DPAdSV & $1.0 \times 10^{-10}-1.0 \times 10^{-8}$ & $2.8 \times 10^{-11}$ & river water samples & This work \\
\hline
\end{tabular}

\subsection{Selectivity of the SPCE/MWCNTs-COOH}

In order to confirm the selectivity of the SPCE/MWCNTs-COOH, the DPAdSV responses of $\mathrm{DF}$ in the presence of different interferences found in environmental water samples were recorded. The tolerance limit was defined as the concentration, which gave an error of $\leq 10 \%$ in the determination of $10.0 \mathrm{nmol} \mathrm{L}^{-1} \mathrm{DF}$. It was noticed that ibuprofen (up to 2000-fold excess), caffeine (up to 2000-fold excess), paracetamol (up to 1000-fold excess), $\mathrm{Ni}^{2+}$ ions (up to 1000 -fold excess), $\mathrm{Fe}^{3+}$ ions (up to 1000-fold excess), $\mathrm{Zn}^{2+}$ ions (up to 500-fold excess), $\mathrm{Pb}^{2+}$ ions (up to 500 -fold excess), $\mathrm{Sb}^{3+}$ ions (up to 500 -fold excess), $\mathrm{Cu}^{2+}$ ions (up to 100 -fold excess), $\mathrm{Cd}^{2+}$ ions (up to 500 -fold excess), $\mathrm{V}^{5+}$ ions (up to 100 -fold excess), and $\mathrm{Mo}^{6+}$ ions (up to 100 -fold excess) had negligible effects (the relative signals were in the range of $93.7-100.1 \%$ ) on the assay of DF. Furthermore, the tolerance limits for the studied surfactants and humic acid were $5.0 \mathrm{mg} \mathrm{L}^{-1}$ for Triton X-100, $1.0 \mathrm{mg} \mathrm{L}^{-1}$ for CTAB, $2.0 \mathrm{mg} \mathrm{L}^{-1}$ for SDS, and $10.0 \mathrm{mg} \mathrm{L}^{-1}$ for humic acid (the relative signals were in the range of 90.4-92.0\%). The results confirmed that the proposed procedure offers good selectivity for the determination of DF and the analysis of environmental water samples can by performed without sample preparation.

\subsection{Application in Environmental Analysis}

In order to evaluate the applicability of the voltammetric procedure with the use of SPCE/MWCNTs-COOH for DF determination in environmental water samples, Vistula river water samples collected from two places, at the sewage outlet (sample \#1) and about 5 kilometres from the outflow of sewage (sample \#2), were analyzed. Table 4 summarizes all results. It should be clearly emphasized that the voltammetric procedure with the use of SPCE/MWCNTs-COOH allowed 
determining DF at a concentration of $0.42 \pm 0.08 \mathrm{nmol} \mathrm{L}^{-1}$ in Vistula river water sample \#1 without sample pretreatment steps (Figure 8). In sample \#2, the DF signal was not visible. The obtained results confirmed the presence of DF in the Vistula river and the dependence of DF concentration on the place of sample collection.

Table 4. Results of DF determination in Vistula river water samples.

\begin{tabular}{|c|c|c|c|c|c|}
\hline \multirow[b]{2}{*}{ Sample } & \multicolumn{3}{|c|}{ DF concentration $\pm S D\left(n m o l ~ L^{-1}\right)(n=3)$} & \multirow{2}{*}{$\begin{array}{c}\text { Recovery (\%) } \\
\text { DPAdSV }\end{array}$} & \multirow[b]{2}{*}{$t_{\text {exp }}$} \\
\hline & Added & $\begin{array}{l}\text { Found with } \\
\text { the DPAdSV } \\
\text { procedure }\end{array}$ & $\begin{array}{c}\text { Found with } \\
\text { the HPLC/PAD } \\
\text { method }\end{array}$ & & \\
\hline$\# 1$ & 0 & $0.42 \pm 0.08$ & - & - & - \\
\hline$\# 1$ & 5.0 & $5.40 \pm 0.20$ & - & 99.6 & - \\
\hline$\# 1$ & 50.0 & $50.80 \pm 1.40$ & $52.30 \pm 4.08$ & 100.5 & 0.60 \\
\hline \#2 & 0 & - & - & - & - \\
\hline \#2 & 0.4 & $0.40 \pm 0.01$ & - & 100.0 & - \\
\hline \#2 & 5.0 & $5.38 \pm 0.33$ & - & 99.6 & - \\
\hline$\# 2$ & 50.0 & $51.0 \pm 0.90$ & $49.80 \pm 4.25$ & 100.9 & 0.48 \\
\hline
\end{tabular}

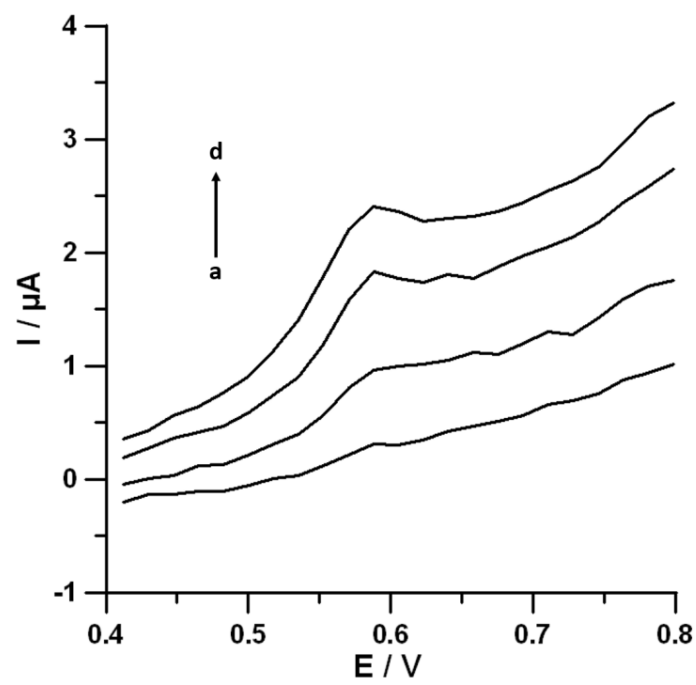

Figure 8. DPAdSV curves recorded at the SPCE/MWCNTs-COOH surface in the course of DF determination in $5 \mathrm{ml}$ Vistula river water sample \#1 without DF (a) and with $0.5 \mathrm{nmol} \mathrm{L}^{-1}$ (b), 1.0 (c) $\mathrm{nmol} \mathrm{L}{ }^{-1}$, and $1.5 \mathrm{nmol} \mathrm{L}^{-1}$ (d) of DF. Other conditions are the same as in Figure 7.

In order to test the accuracy of the DPAdSV method, samples were spiked with a standard solution of DF. The recovery values attained by the DPAdSV method were between $99.6 \%$ and $100.9 \%$, which corresponded to the satisfactory degree of accuracy.

The results with the DPAdSV method were compared with those obtained by the chromatographic method, HPLC/PAD. As can be seen in Table 4, the HPC/PAD method allowed determining DF in river water samples at a concentration of $10.0 \mathrm{nmol} \mathrm{L}^{-1}$, which was significantly above the real DF concentration in water samples. In order to determine lower concentrations of DF by the chromatographic method, an additional sample preparation step was required. According to the Student's t-test, there were no significant differences between DF concentrations obtained by both methods. The calculated $t$ values $\left(t_{\exp }\right)$ were 0.48 and 0.60 , which were below the critical value equal to 1.81 (for degrees of freedom $\mathrm{f}$ equal to $4\left(\mathrm{f}=\mathrm{n}_{1}+\mathrm{n}_{2}-2\right)$ and $95 \%$ confidence level). All these results indicated that the DPAdSV procedure using an SPCE/MWCNTs-COOH is highly selective and excellent for the determination of DF in real applications. 


\section{Conclusions}

In summary, a simple, sensitive and time-saving DPAdSV procedure using an SPCE/MWCNTs-COOH was presented and successfully applied for the determination of DF. The modified sensor showed an improved sensing activity towards DF compared to a bare SPCE due to the effect of the modifier. The use of carboxyl functionalized MWCNTs improved the electron transfer process and the active surface area of the sensor. The SPCE/MWCNTs-COOH exhibited excellent current responses towards DF determination in the linear range of $0.1-10.0 \mathrm{nmol} \mathrm{L}^{-1}$ and an LOD value of $0.028 \mathrm{nmol} \mathrm{L}^{-1}$. Furthermore, the SPCE/MWCNTs-COOH also showed satisfactory repeatability, reproducibility, and selectivity towards potential interferences. It should be clearly stressed that, for the first time, the electrochemical sensor was used for the determination of a real concentration of $\mathrm{DF}\left(0.42 \pm 0.08 \mathrm{nmol} \mathrm{L}^{-1}\right)$ in environmental water samples (Vistula river samples) without sample pretreatment steps. All these discussion indicated that the DPAdSV procedure using an SPCE/MWCNTs-COOH has great potential towards the determination of DF in real water samples to maintain environmental protection. Moreover, the DPAdSV procedure using an SPCE/MWCNTs-COOH can be applied in the DF field analysis.

Author Contributions: Conceptualization, A.S. and K.T.-R.; methodology, A.S. and K.T.-R.; investigation, A.S., K.T.-R., M.W., and I.S.; writing of the original draft preparation, A.S. and K.T.-R.; writing of review and editing, A.S., K.T.-R., M.W., and I.S.; supervision, K.T.-R. All authors have read and agreed to the published version of the manuscript.

Funding: This research no external funding.

Acknowledgments: The research was carried out with the equipment purchased, thanks to the financial support of the European Regional Development Fund in the framework of the Polish Innovation Economy Operational Programme (contract no. POIG.02.01.00-06-024/09 Centre for Functional Nanomaterials).

Conflicts of Interest: The authors declare no conflict of interest.

\section{References}

1. Mekassa, B.; Baker, P.G.L.; Chandravanshi, B.S.; Tessema, M. Synthesis, characterization, and preparation of nickel nanoparticles decorated electrochemically reduced graphene oxide modified electrode for electrochemical sensing of diclofenac. J. Solid State Electrochem. 2018, 22, 3607-3619. [CrossRef]

2. Valcarcel, Y.; Gonzales Alonso, S.; Rodriguez-Gil, J.L.; Romo Maroto, R.; Gil, A.; Catala, M. Analysis of the presence of cardiovascular and analgesic/anti-inflammatory/antipyretic pharmaceutical in rivier- and drinking- water of the Madrid Region in Spain. Chemosphere 2011, 82, 1062-1071. [CrossRef] [PubMed]

3. Kosjek, T.; Heath, E.; Krbavcic, A. Determination of non-steroidal anti-inflammatory drug (NSAIDs) residues in water samples. Environ. Int. 2005, 31, 679-685. [CrossRef] [PubMed]

4. Rizzo, L.; Meric, S.; Kassinos, D.; Guida, M.; Russo, F.; Belgiorno, V. Degradation of diclofenac by $\mathrm{TiO}_{2}$ photocatalysis: UV absorbance kinetics and process evaluation through a set of toxicity bioassays. Water Res. 2009, 43, 979-988. [CrossRef] [PubMed]

5. Taggart, M.A.; Senacha, K.R.; Green, R.E.; Jhala, Y.V.; Raghavan, B.; Rahmani, A.R.; Cuthbert, R.; Pain, D.J.; Meharg, A.E. Diclofenac residues in carcasses of domestic ungulates available to vultures in India. Environ. Int. 2007, 33, 759-765. [CrossRef] [PubMed]

6. Sanderson, H.; Johnson, D.; Wilson, C.; Brain, R.; Solomon, K. Probabilistic hazard assessment of environmentally occurring pharmaceuticals toxicity to fish, daphnids and algae by ECOSAR screening. Toxicol. Lett. 2003, 144, 383-395. [CrossRef]

7. Cleuvers, M. Mixture toxicity of the anti-inflammatory drugs diclofenac, ibuprofen, naproxen, and acetylsalicylic acid. Ecotoxicol. Environ. Saf. 2004, 59, 309-315. [CrossRef]

8. Pandey, G. Spectrophotometric, chromatographic and spectrofluorometric methods for the determination of diclofenac: A review. Pharm. Lett. 2011, 3, 257-265.

9. Gouda, A.A.; Kotb El-Sayed, M.I.; Amin, A.S.; Sheikh, R.E.L. Spectrophotometric and spectrofluorometric methods for the determination of non-steroidal anti-inflammatory drugs: A review. Arab. J. Chem. 2013, 6, 145-163. [CrossRef] 
10. Heli, H.; Jabbari, A.; Majdi, S.; Mahjoub, M.; Moosavi-Movahedi, A.A.; Sheibani, S.H. Electrooxidation and determination of some non-steroidal anti-inflammatory drugs on nanoparticles of Ni-curcumin-complex-modified electrode. J. Solid State Electrochem. 2009, 13, 1951-1958. [CrossRef]

11. Afkhami, A.; Bahiraei, A.; Madrakian, T. Gold nanoparticle/multi-walled carbon nanotube modified glassy carbon electrode as a sensitive voltammetric sensor for the determination of diclofenac sodium. Mater. Sci. Eng. C 2016, 59, 168-176. [CrossRef] [PubMed]

12. Arvand, M.; Gholizadeh, T.M.; Zanjanchi, M.A. MWCNTs/Cu(OH)2 nanoparticles/IL nanocomposite modified glassy carbon electrode as a voltammetric sensor for determination of the non-steroidal anti-inflammatory drug diclofenac. Mater. Sci. Eng. C 2012, 32, 1682-1689. [CrossRef] [PubMed]

13. Razmi, H.; Sarhang-Zadeh, K.; Mohammad-Rezaei, R. Electrochemical behavior and voltammetric determination of diclofenac at a multi-walled carbon nanotube-ionic liquid composite modified carbon Cceramic electrode. Anal. Lett. 2013, 46, 1885-1896. [CrossRef]

14. Karuppiah, C.; Cheemalapati, S.; Chen, S.M.; Palanisamy, S. Carboxyl-functionalized graphene oxide-modified electrode for the electrochemical determination of nonsteroidal anti-inflammatory drug diclofenac. Ionics 2015, 21, 231-238. [CrossRef]

15. Jiokenga, S.L.Z.; Tonlea, I.K.; Walcariusb, A. Amino-attapulgite/mesoporous silica composite films generated by electroassisted self-assembly for the voltammetric determination of diclofenac. Sens. Actuators B Chem. 2019, 287, 296-305. [CrossRef]

16. Okoth, O.K.; Yan, K.; Liu, L.; Zhang, J. Simultaneous electrochemical determination of paracetamol and diclofenac based on poly(diallyldimethylammonium chloride) functionalized graphene. Electroanalysis 2016, 28, 76-82. [CrossRef]

17. Yang, X.; Wang, F.; Hu, S. Enhanced oxidation of diclofenac sodium at a nano-structured electrochemical sensing film constructed by multi-wall carbon nanotubes-surfactant composite. Mater. Sci. Eng. C 2008, 28, 188-194. [CrossRef]

18. Kashefi-Kheyrabadi, L.; Mehrgardi, M.A. Design and construction of a label free aptasensor for electrochemical detection of sodium diclofenac. Biosens. Bioelectron. 2012, 33, 184-189. [CrossRef]

19. Kamenická, B.; Bartášková, A.; Švancara, I.; Weidlich, T. Applicability of voltammetric determination of diclofenac at carbon paste electrodes to the analysis of aqueous solutions purified by adsorption and/or ionic liquid based ion exchange. Mon. Chem. 2019, 150, 429-437. [CrossRef]

20. Damiri, S.; Oskoei, Y.M.; Fouladgar, M. Highly sensitive voltammetric and impedimetric sensor based on an ionic liquid/cobalt hexacyanoferrate nanoparticle modified multiwalled carbon nanotubes electrode for diclofenac analysis. J. Exp. Nanosci. 2016, 11, 1384-1401. [CrossRef]

21. Arvand, M.; Hassannezhad, M. Square wave voltammetric determination of uric acid and diclofenac on multi-walled carbon nanotubes decorated with magnetic core-shell $\mathrm{Fe}_{3} \mathrm{O}_{4} @ \mathrm{SiO}_{2}$ nanoparticles as an enhanced sensing interface. Ionics 2015, 21, 3245-3256. [CrossRef]

22. Mokhtaria, A.; Karimi-Malehb, H.; Ensafic, A.A.; Beitollahi, H. Application of modified multiwall carbon nanotubes paste electrode for simultaneous voltammetric determination of morphine and diclofenac in biological and pharmaceutical samples. Sens. Actuators B Chem. 2012, 169, 96-105. [CrossRef]

23. Ensafi, A.A.; Izadi, M.; Karimi-Maleh, H. Sensitive voltammetric determination of diclofenac using room-temperature ionic liquid-modified carbon nanotubes paste electrode. Ionics 2013, 19, 137-144. [CrossRef]

24. Goodarzian, M.; Khalilzade, M.A.; Karimi, F.; Gupta, V.K.; Keyvanfard, M.; Bagheri, H.; Fouladgar, M. Square wave voltammetric determination of diclofenac in liquid phase using a novel ionic liquid multiwall carbon nanotubes paste electrode. J. Mol. Liq. 2014, 197, 114-119. [CrossRef]

25. Pourghobadi, R.; Baezzat, M.R. Silica nanoparticles modified carbon paste electrode as a voltammetric sensor for determination of diclofenac. Anal. Bioanal. Chem. Res. 2017, 4, 261-268.

26. Chethana, B.K.; Basavanna, S.; Naik, Y.A. Voltammetric determination of diclofenac sodium using tyrosine-modified carbon paste electrode. Ind. Eng. Chem. Res. 2012, 51, 10287-10295. [CrossRef]

27. Blanco-Lopez, M.C.; Fernandez-Llano, L.; Lobo-Castanon, M.J.; Miranda-Ordieres, A.J.; Tunon-Blanco, P. Voltammetry of diclofenac at graphite, carbon Composites, and molecularly imprinted polymer-composite electrodes. Anal. Lett. 2004, 37, 915-927. [CrossRef]

28. Goyal, R.N.; Chatterjee, S.; Agrawal, B. Electrochemical investigations of diclofenac at edge plane pyrolytic graphite electrode and its determination in human urine. Sens. Actuators B Chem. 2010, 145, 743-748. [CrossRef] 
29. Manea, F.; Ihos, M.; Remes, A.; Burtica, G.; Schoonmanc, J. Electrochemical determination of diclofenac sodium in aqueous solution on $\mathrm{Cu}$-doped zeolite-expanded graphite-epoxy electrode. Electroanalysis 2010, 22, 2058-2063. [CrossRef]

30. Sarhang-Zadeh, K.; Khatami, A.A.; Jabbari, M.; Bahari, S. Simultaneous determination of diclofenac and indomethacin using a sensitive electrochemical sensor based on multiwalled carbon nanotube and ionic liquid nanocomposite. J. Appl. Electrochem. 2013, 43, 1217-1224. [CrossRef]

31. Ihosa, M.; Remesb, A.; Maneab, F. Electrochemical determination of diclofenac using boron-doped diamond Electrode. J. Environ. Prot. Ecol. 2012, 13, 2096-2103.

32. Yilmaz, B.; Kaban, S.; Akcay, B.K.; Ciltas, U. Differential pulse voltammetric determination of diclofenac in pharmaceutical preparations and human serum. Braz. J. Pharm. Sci. 2015, 51, 285-294. [CrossRef]

33. Ciltas, U.; Yilmaz, B.; Kaban, S.; Akcay, B.K.; Nazik, G. Square wave voltammetric determination of diclofenac in pharmaceutical preparations and human serum. Iran. J. Pharm. Res. 2015, 14, 715-722. [PubMed]

34. Renedo, O.D.; Alonso-Lomillo, M.A.; Arcos Martinez, M.J. Recent development in the field of screen-printed electrodes and their related applications. Talanta 2007, 73, 202-219. [CrossRef] [PubMed]

35. Golzari Aqda, T.; Behkami, S.; Bagheri, H. Porous eco-friendly fibers for on-line micro solid-phase extraction of nonsteroidal anti-inflammatory drugs from urine and plasma samples. J. Chromatogr. A 2018, 1574, 18-26. [CrossRef] [PubMed]

36. Sipa, K.; Brycht, M.; Leniart, A.; Nosal-Wiercińska, A.; Skrzypek, S. Improved electroanalytical characteristics for the determination of pesticide metobromuron in the presence of nanomaterials. Anal. Chim. Acta 2018, 1030, 61-69. [CrossRef]

37. Cid-Cerón, M.M.; Guzmán-Hernández, D.S.; Ramírez-Silva, M.T.; Galano, A.; Romero-Romo, M.; Palomar-Pardavé, M. New insights on the kinetics and mechanism of the electrochemical oxidation of diclofenac in neutral aqueous medium. Electrochim. Acta 2016, 199, 92-98. [CrossRef]

38. Tyszczuk-Rotko, K.; Pietrzak, K.; Sasal, A. Adsorptive stripping voltammetric method for the determination of caffeine at integrated three-electrode screen-printed sensor with carbon/carbon nanofibers working electrode. Adsorption 2019, 25, 913-921. [CrossRef]

39. Laviron, E. General expression of the linear potential sweep voltammogram in the case of diffusionless electrochemical systems. J. Electroanal. Chem. 1979, 101, 19-28. [CrossRef]

40. Medsen, K.G.; Skonberg, C.; Jurva, U.; Cornett, C.; Hansen, S.H.; Johansen, T.N.; Olsen, J. Bioactivation of diclofenac in vitro and In Vivo: Correlation to electrochemical studies. Chem. Res. Toxicol. 2008, 21, 1107-1119. [CrossRef]

41. Mocak, J.; Bond, A.M.; Mitchell, S.; Scollary, G. A statistical overview of standard (IUPAC and ACS) and new procedures for determining the limits of detection and quantification: Application to voltammetric and stripping techniques. Pure Appl. Chem. 1997, 69, 297-328. [CrossRef] 